\section{Leitfähigkeit des Urins}

W. G. Guder

München, Deutschland

Synonym(e) elektrische Leitfähigkeit

Englischer Begriff conductivity of urine

Beschreibung Moderne Messinstrumente zur Überwachung des Urinflusses von Intensivpatienten, Auswertung von Teststreifen (z. B. Aution Max, Menarini) oder zur Analyse der Partikel im Urin (z. B. UF 100 und UN mit UC Teststreifenanalysator Sysmex, iQ200, Iris und FUS-2000 von Diriu Industrial Comp) haben eine Leitfähigkeitsmessung der Urine eingebaut, um die Konzentration des Urins zu messen. Die Leitfähigkeit ist jedoch im Wesentlichen abhängig von der Zahl der elektrisch leitenden Teilchen (d. h. Ionen). Eine Untersuchung bei Patienten ergab, dass die $>$ Leitfähigkeit des Urins am besten korreliert mit der Summe der Konzentrationen von Natrium und Kalium $(\mathrm{R}=0,873)$, schwächer mit der $>$ Osmolalität $(\mathrm{R}=0,732)$ und schlecht mit der relativen Dichte $(\mathrm{R}=0,628)$. Bei Intensivpatienten war diese
Korrelationen noch schwächer. Mit dem Teststreifenergebnis, bei dem ebenfalls die Dichte der Kationen als Maß für das spezifische Gewicht verwendet wird, war die Korrelation noch schlechter. Dennoch wird die Leitfähigkeit bei allen medizinischen Anwendungen in relativer Dichte angegeben, die mit empirisch ermittelten Korrelationsgleichungen bei Normalen umgesetzt wird:

Relative Dichte $=\mathrm{A} \times$ Leitfähigkeit $(\mathrm{S})+\mathrm{B}$

$\mathrm{A}=$ Korrelationsfaktor bei Normalpersonen, $\mathrm{B}=$ Schnittpunkt der Korrelation mit der $\mathrm{y}$-Achse, $\mathrm{S}=$ Leitfähigkeit in Siemens.

Aus diesem Grund sind auch keine Normalbereiche in Siemens angegeben; vgl. \ Gewicht, spezifisches des Urins.

\section{Literatur}

Guder WG (2009) Osmolalität, Leitfähigkeit, spezifisches Gewicht des Harns. In Guder WG, Nolte J. Das Laborbuch für Klinik und Praxis. 2. Aufl. München: Elsevier, Urban und Fischer, S 954-5

Hofmann W, Miller B, Guder WG (1996) Spezifisches Gewicht, Leitfähigkeit, Dichte und Osmolalität im Harn. Vergleich bei Normalpersonen, stationären Patienten und Intensivpatienten. J Lab Med 20:697-703 